\title{
Asian ethnic sports culture development is analysed
}

\author{
Ming Zha \\ School of Chinese Language and Literature, China West Normal University, Nanchong 637002, China
}

\begin{abstract}
Asia is the world's largest population, a continent, has the traditional culture of bright, has created the Oriental civilization, a symbol of national sports is a particularly significant. Asian national sport as an important part of the Asian culture, the two complement each other, is inseparable from the development up to now. Asian ethnic sports from a new Angle to show the special performance of people and society and nature, and is to people's creativity and talent development degree of identification. As a result, Asian ethnic sports is not only a sports phenomenon, more specifically it is a cultural phenomenon. Search for Asian culture historical development process, it is not difficult to understand the Asian sports culture formation, evolution and propagation reaction to the best of ancient Asian civilizations, and showed the different ethnic groups with Europe and the United States sports sports culture and value.
\end{abstract}

\section{Introduction}

According to the geographical distribution of Asia can be divided into east Asia, west Asia, South Asia, north Asia, southeast Asia and central Asia, according to the different geographical distribution, formed the different regional sports culture, thus formed the different culture area, thus has produced different sports culture and civilization.

Refers to the east of Asia, east Asia, including China, South Korea, north Korea, Japan and Mongolia, population distribution is one of the most densely populated region in the world. The basic elements of east Asian culture area is han type text, Confucianism, Chinese laws system and agricultural technology, Buddhism. These elements on the language forms of east Asian countries, ideology, social organizations, productivity development and the influence of mode of production to be extremely deep. The Chinese culture to the influence of the three countries such as Vietnam is divided into three levels and the extended four bond maintaining culture area in East Asia. Three levels are: material culture, ancient Chinese national migration interdependent family has three kingdoms in the name of the Chinese characters and the influence of rice culture; spiritual culture: the main is the spread of Confucianism and Buddhism; the system culture: the main is adopted and the spread of the rule of law. Four link is: Chinese characters of the application of the same firm heart foundation; the spirit of Confucianism to promote cultural integration; sustaining common belief in Chinese Buddhism, Article of the ancient Chinese ethnic regimes around the law to maintain order [1-3].

Have appeared on the original era of Chinese medical gymnastics a pragmatic prototype dance, detumescence, it is a swelling effect of health sports activities. Cuju movement during the warring states period, the western zhou dynasty in the education system, have been riding (now) for horseback riding, archery and other sports [4-7]. The zhou dynasty "the ritual", at the time of qin and han dynasties Angle on the play, the entertainment games and body-keeping for shousands of northern and southern dynasties, the tang dynasty after the military martial arts and sports activities, sports organizations and wrestling appeared in song dynasty, yuan dynasty long distance of the Ming and qing dynasties martial arts are famous all over the world. East Asian cultures in other countries and the influence of China's own development has formed in the process of their respective national culture characteristics of sports. Swinging on North Korea, the springboard, the urn walking and tae kwon do, Japanese sumo, karate, kendo, bows, Mongolia's "three boys art," said the archery, wrestling and horse racing.

\section{The development of national sports culture in Asia}

\subsection{Culture area in South Asia}

South Asia to South Asia, including Sri Lanka, the maldives, Pakistan, India, Bangladesh, Nepal and other countries. Culture one of the representatives of the countries in the area of India, the country's Hindu, "one of the four ancient civilizations" in India, more than four thousand years ago there is a high level of social and cultural development.

Ancient India undertakings of physical culture and sports has obvious racial hierarchy specification, only the

a Corresponding author: 3060075903@qq.com. 
ruler and racial supremacy of Ann talent of military sports or riding and shooting, etc., and practice. Also, because of the different religious beliefs to bring local impact on the development of sports culture is negative. But sports fitness art "yoga" quite accord with religious doctrine developed by early instead. The size specification of yoga ancient and easy to understand method, improved the ability of people in every aspect, uniform harmony of body and mind is a form of exercise, and easy to realize the unity of body and mind. In ancient times, in the southwest of the Indian has a ground, there is a kind of auspicious motion of the snake - snake game, like the Chinese Dragon Boat Festival dragon boat race, this is also a sports, handed down from ancient India. South Asian culture in other countries, Sri Lanka to climb trees, coconut, Angle, and keep the game in Pakistan such as sports is a part of national sports in east Asia [8].

\subsection{Culture area}

Refers to the western Asia, including Jordan, Afghanistan, Turkey, Kuwait, Iran, Syria, Palestine, Israel, Iraq, Lebanon, Saudi Arabia and so on more than a dozen countries. Mostly in Arab countries, mainly Muslim, culture lasting appeal is very heavy, but the mechanical civilization is relatively backward.

In ancient times, the two river basin of josiah gave birth to the brilliant civilization and its sports culture. Ancient sports - sticks to hit the ball is in the side of soil. Iran called the Persian, once created the ancient Persian culture of bright, Persian empire in the national small put strict spears, archery and other military sports practice, adulthood will join the army, the exercise out of the military sports in Asia continent extremely has the capability of military power in Asia.

\subsection{Cultural area of Southeast Asia}

Refers to the Southeast Asian region of Southeast Asia, including Malaysia, Cambodia, Vietnam, Laos, myanmar, Thailand, Singapore, more than a dozen countries and regions such as east timor. Southeast Asian countries have extremely vast natural resources and abundant human resources, which provides convenient conditions for economic development, has formed is given priority to with monsoon and tropical paddy agriculture plantation of regional agricultural type. But the economic structure is unitary. Since the 20th century $60 \mathrm{~s}$, developed countries to the appearance of the market economy and state intervention combined with comprehensive economic progress mode. Religious beliefs, and language of southeast Asian nations is multifarious, internal difference is very big, is the influence of cultural differences between the two countries part is influenced by European and American cultural differences, the social consciousness, social cultural form numerous and complicated clutter.

Southeast Asia each nation in the long social life, according to each country's geography, culture, and survival mode of production and different in folk custom create colorful traditional sports in a wide range of entertainment. Such as Thailand, myanmar, Malaysia, Indonesia boatrace, muay Thai, gyro, cane, paper warbler, stone horse, cow, frog RACES, running water, cane, swing and other sports entertainment.

\section{The development of national sports in Asia}

Oriental culture including the philosophy of the Oriental nation thought forms, customs, religious consciousness and aesthetic concept of different aspects, such as. The national sports promote the various countries' culture in many aspects, all-round development, that is, the national sports in Asia is not the same way, the different channels, different degree of penetration and promote the advance of culture development. Such as national leisure education and mode of production, medical, fitness, wind price, ethics, ideology, art, art of war, system, chess, and has close relation with the life style and cultural phenomenon. Different regions, different living environment and working conditions for humans, to a certain extent caused the human society production mode, life style and thinking mode difference, form different social psychology and cultural form. Sports, as a special cultural traits behavior, due to the geographical environment and social development back and ethnic differences in cultural mentality, will present different characteristics of sports culture, with a particular social history and culture.

Such as spread from ancient to modern Chinese qigong to form a good sports. Qigong is a comprehensive method of preserve one's health. In physical activities of the adjustment, the change of ideology (pranayama, adjustment, and the heart) and breathing for methods and in order to achieve health for the results of a physical and mental exercise method. Major is management of natural gas and congenital qi unity relations, the Chinese qigong in congenital qi from their parents. Qigong has various complex types. The move work for physical activity of qigong, features to pay attention to the body of the unity of spirit in action. Members one of another kind of static power is fixed, only rely on the application of this spirit, consciousness of self-adjusting to qigong. And most qigong method is static. In religions, of which Taoist monks often training guidance, internal Dan qigong, sit-ins also contains qigong.

The early individual Asian countries monarchy early mature and fully developed. Corresponding appeared to be suitable for separating system, patriarchal authoritarian regimes in the form of ideology and social culture, the influence of this series is also inevitable radiation to the preliminary formation and development of sports culture, ancient Asian sports are deeply printed on hierarchical society. In ancient times, which features the same norms of ancient sports specifically. Make its "appearance yan zhuang", even if the behavior of the instrument is feudal ethical norms, the premise of "swimming in arts", must be "in a way, according to virtue, in accordance with the union special". "Shooting ceremony" is the ancient Chinese national express national etiquette is an important form of expression, represents the consciousness of the Chinese nation, character, temperament, and many other 
aspects, is a kind of special humanities landscape in ancient times the Chinese nation. But the same archery also exist different hierarchies, namely, "bing", "big shot", "township", "yan". In Asia this hierarchy with the democratization of western sports is in stark contrast.

Again, such as India yoga is known as the "treasure of the world", a history of more than 5000 years ago has been used by people. Again, such as Japan's judo is compelling national sports. Judo is free of competitive sports, its athletics is obviously higher than that of Chinese qigong and yoga in India. Judo can be the most effective use of the white body ability, attack and defense are exquisite, firm soft with mutually, can make the body strength and quality of god are a workout and development. Judo in Japan, has developed into the world, is the 18th Olympic Games listed as official event. Judo for the quality of Japanese national spirit, the will, accomplishment, bearing, and habit good played a role cannot be underestimated.

Asia's national sport is a product combining material civilization and spiritual civilization of the east, it showed both Oriental national leisure concept of leisure education and YuLeGuan, and pursuit of countries strongly all the planning and implementation. National sports is not only physical exercise, and industrial and agricultural production can bring direct and indirect means of training, make the combination of material civilization and spiritual civilization. Asian civilizations, local conditions and customs of the east is popular in the world. Asia culture, promoting the national Hugh nurtures the emergence, development and variation of dash. National sports consciousness and life mode of production, spirit forms three types of culture affect each other, each other the product of the combination of the premise, organized. Oriental countries have their praise highly religious and moral philosophy, have their differences life mode of production, and have their unique spirit pursuit, when these three closely combined together, the resulting in the true sense of the Oriental civilization. For mainland culture and tonal and western Marine culture essence of Orient culture appears in the world, national sports is the product of the culture in Asia.

\section{The evolutionary significance of national sports culture in Asia}

Asian sports culture, sports and culture not only for Asian countries to help and promote the development of function, and to build the world sports culture of the new situation, to promote human made special contribution to the development of physical education and health undertakings.

\subsection{Fill the deficiency of the modern world of competitive sports}

The development of human culture, the beginning is in the progress of each other completely different environment, they have their respective has the characteristics of every part of the external form, thus constitute each other different culture idea, thought mode, behavior way, value concept and national sports spirit. And with the coming of the industrial society, broke the world culture, geographical environment and human environment by the diaphragm. To promote the development of world sports culture showed a new situation, also is the culture of each region, each nation to the nature of the variety, of worldwide recognition, gradually formed from the culture of the individual to the cultural choice of the mode of comprehensive development of the world culture of Asian sports and western sports continuously interaction sowing and the culvert, common input system of the Olympic culture around the world, promoting the prosperity of the world sports culture and prosperity. Originated from ancient Chinese football, in the kingdom of Persia polo, initiation civilization of ancient India badminton, popular development in Japanese folk judo sport has the world sports development orbit. Chinese martial arts, the north of tae kwon do is move towards the world with its special charm. China go, India has fully into the world chess, chess gradually let the people of all countries, to accept. All of these to the prosperity of the world sports culture has made a significant contribution.

\subsection{The world sports culture can show expands the function of the structure}

Under the influence of the high-tech technology revolution, the contemporary society is in the direction of the information management system of automation, DianQiHua, continuous development. Technology makes an ever-upward trajectory for social material wealth, but also bring bad influence to human health, such as the urban population intensive, the ecological environment is getting worse, social competition is increasingly fierce, so that industrialized countries growing social "civilized disease" phenomenon, human body function decline. This makes healthy Asian sports to good development, the value of the corresponding spreading ideology and culture. Not only that, the western sports also use Indian yoga and Chinese qigong aspects to regulate the field competitive athletes psychological changes and recovery after the event. Further, the western physiology in the medical community with their own technology for Indian yoga and qigong, etc to do more detailed research in China. That is to say, the fusion of eastern and western sports culture is undergoing an unprecedented and mutual promoting development.

\section{Conclusion}

To sum up, in the long process of human development, because in the national traditional, history, geography, a very different aspects, such as the eastern and western cultures for the roots grow shows different forms. And derivative of eastern and western sports culture in the process, they gathered the fundamental thought and mental characteristics of its parent culture, manifests the national characteristics of a certain height. Asia's 
traditional national sports culture with the west's most competitive sports culture of the unity of opposites is objective, it will not only change the characteristics of the original sports culture, but also because of developing sports culture, gives birth to a new agreement with those obtained resulting in the change of culture. So the people of the world should correctly treat the advantages and disadvantages of the east and western sports culture and cultural exchanges between the two sports phenomenon, for the world sports culture colorful and Asian sports culture contribution to carry forward their own a strength.

\section{References}

1. Rao Yuan. Journal of sports literature. 43-44 (2002).
2. L. Jun, L.J. Mo, et al., Journal of sports adult education. 26, 1672-268 (2010).

3. C.F. Tu, Z.D. Chen, Y. Wei, et al., Journal of wuhan sports college. 9, 24-31 (2007).

4. Z.R. Huang. The 16th Asian Games science congress proceedings. 28-29 (2010).

5. G. Wang, E. Mikami, L.L Chiu, et al., Medicine and science in sports and exercise. 45, 892-900 (2013).

6. J.X. Song. The 16th Asian Games science congress proceedings.16-17 (2010).

7. X.P. Song. The 16th Asian Games science congress proceedings. 79-80 (2010).

8. W.T. Guo. The 16th Asian Games science congress proceedings. 384-385 (2010). 